\title{
COMPONENTES GENÉTICOS DO DESENVOLVIMENTO E MATURAÇÃO DE FRUTOS DE Coffea canephora Pierre ex A.Froehner
}

\author{
Carolina Augusto de Souza ${ }^{1}$, Rodrigo Barros Rocha², Enrique Anastácio Alves ${ }^{3}$, \\ Marcelo Curitiba Espindula ${ }^{4}$, André Rostand Ramalho ${ }^{5}$, Alexsandro Lara Teixeira ${ }^{6}$, \\ Maria Amélia Gava Ferrão ${ }^{7}$
}

(Recebido: 30 de agosto de 2016; aceito: 21 de novembro de 2016)

\begin{abstract}
RESUMO: O ciclo de maturação dos frutos do cafeeiro Coffea canephora é uma característica de herança complexa, de expressão governada por vários genes influenciados pelo ambiente, o que resulta em uma característica quantitativa de distribuição contínua. O objetivo desse trabalho foi caracterizar os componentes genéticos do ciclo de maturação dos frutos de $C$. canephora visando caracterizar o mecanismo de herança e a influência do ambiente na expressão dessa característica. Para isso foram avaliados o número de dias e a soma térmica para a maturação dos frutos de 130 clones, avaliados ao longo de 36 meses, em delineamento de blocos ao acaso com seis repetições de quatro plantas por parcela no município de Ouro Preto do Oeste RO. Os valores genotípicos e os componentes de variância foram estimados utilizando-se métodos de Máxima Verossimilhança Restrita (REML) e Melhor Predição Linear Não Viesada (BLUP) e a dissimilaridade entre os genótipos quantificada utilizando técnicas de agrupamento hierárquico. As estimativas dos parâmetros genéticos indicam maior acurácia da soma térmica para estimar o ciclo de maturação dos frutos, e uma predominância do efeito genotípico na expressão dessa característica. No dendrograma foi possível observar três grupos de maturação distintos que se mantiveram ao longo do tempo. Também foram observados genótipos (20\%) que apresentaram mudanças em sua classificação devido à ação do ambiente. A quantificação da eficiência da seleção e o agrupamento dos clones de ciclo de maturação semelhante subsidiam o desenvolvimento de novas variedades de maior uniformidade de maturação de frutos.
\end{abstract}

Termos para indexação: Ciclo de maturação, acurácia de seleção, soma térmica, Amazônia, Rondônia.

\section{GENETIC COMPONENTS FOR FRUIT DEVELOPMENT AND RIPENING OF Coffea canephora Pierre ex A. Froehner}

ABSTRACT: Although normally measured in classes, fruit ripening cycle is a complex trait with expression governed by several genes influenced by the environment, which results in a quantitative trait of the continuous distribution. This study aimed to characterize the genetic components of Coffea canephora fruits ripening cycle in order to quantify the genotypic and environmental effects in the expression of this trait. The number of days and the thermal time for fruit ripening of 130 clones were evaluated over 36 months in design of randomized blocks with six replicates of four plants per plot in OuroPreto do Oeste - RO. The genotypic values and the variance components were estimated using methods of Restricted Maximum Likelihood (REML) and Best Linear not Unbiased Prediction (BLUP) and the dissimilarity among genotypes quantified using hierarchical clustering techniques. Estimates of genetic parameters indicate greater accuracy of thermal time to estimate the fruit ripening cycle, and a predominance of the genotypic effect on the expression of this trait. In the dendrogram it was possible to observe three different fruit ripening groups, which maintained over time. They were also observed genotypes (20\%) that changed their classification due to the environmental effect. The observed efficiency of selection associated and the clustering of genotypes with similar ripening cycles subsidize the development of new varieties.

Index terms: Ripening cycle, accuracy of selection, thermal time, Amazonian, Rondônia.

\section{INTRODUÇÃO}

O cafeeiro pertence ao gênero Coffea spp. o qual possui 124 espécies, encontradas atualmente em regiões tropicais de todo o mundo (DAVIS et al., 2011). Desse conjunto duas espécies são cultivadas em larga escala para comercialização, o $C$. arabica L. e o C. canephora. Essas espécies diferenciam-se em relação a características morfológicas e genéticas. Aproximadamente 38\% da produção de café do mundo deve-se ao cultivo da espécie C. canephora, que se caracteriza pelo elevado vigor vegetativo e produção de uma com alto teor de sólidos solúveis (MOURA et al., 2007;
RIBEIRO et al.,2014). Na Amazônia Ocidental destaca-se o Estado de Rondônia pela sua aptidão para cultivo do $C$. canephora (PEZZOPANE et al., 2010; ROCHA et al., 2014).

O conhecimento da época de maturação dos frutos do cafeeiro é fundamental, pois facilita a colheita, o beneficiamento e a comercialização dos frutos (PARTELLI et al., 2010). Segundo Petek, Sera e Fonseca (2009) o ciclo de maturação do cafeeiro pode ser entendido como o período fenológico de desenvolvimento e maturação dos frutos, que ocorre entre o florescimento e a colheita.

\footnotetext{
${ }^{1}$ Programa de Desenvolvimento Regional e Meio Ambiente da Universidade Federal de Rondônia - PGDRA/UNIR - Campus José Ribeiro Filho, BR 364 km 9,5 - 76.801-059 - Porto Velho - RO - carolina augusto@hotmail.com

2,3,4,5,6 Empresa Brasileira de Pesquisa Agropecuária - Embrapa Rondônia - BR 364 - Km 5,5 - Zona Rural - 76.815-800 Porto Velho - RO - rodrigo.rocha@embrapa.br,enrique.alves@embrapa.br, marcelo.espindula@embrapa.br, andre.rostand@embrapa.br,alexsandro.teixeira@embrapa.br

${ }^{7}$ Embrapa Café/Incaper - Parque Estação Biológica, PqEB, s/n - 70.770-901 - Brasília - DF - maria.ferrao@embrapa.br
}

Coffee Science, Lavras, v. 12, n. 3, p. 355 - 364, jul./set. 2017 
O ciclo fenológico dos cafeeiros apresenta uma sucessão de fases vegetativas e reprodutivas que ocorrem em aproximadamente dois anos. A fase reprodutiva se caracteriza pelo desenvolvimento das gemas axilares em gemas reprodutivas (CUNHA; VOLPE, 2011; PARTELLI et al., 2014). Após a fecundação e queda das flores inicia-se a fase da frutificação, culminando em um período de aparente dormência, mas de intensa atividade celular. Posteriormente os frutos passam por um período de expansão celular e de alta demanda hídrica, em que os frutos se desenvolvem rapidamente, aumentando em volume e massa seca (PEZZOPANE et al., 2003; REZENDE et al., 2007). Cada estágio de formação possui funções fisiológicas e metabólicas próprias, essenciais à formação do café (LAVIOLA et al., 2007). Além dos fatores ambientais, fatores genéticos são determinantes para o ciclo de maturação dos frutos podendo ser encontradas em campo plantas que amadurecem em diferentes épocas do ano (PETEK; SERA; FONSECA, 2009; PEZZOPANE et al., 2003). Dubberstein et al. (2016) caracterizaram genótipos de C. canephora propagados vegetativamente (clones) com ciclo de maturação de aproximadamente 300 dias. Em campo, de maneira prática, os clones de $C$. canephora que amadurecem nos meses de abril, maio e junho são denominados respectivamente clones de ciclo precoce, intermediário e tardio. Ferrão et al. (2008) caracterizam genótipos de ciclo super precoce que apresentaram maturação de frutos no mês de março.

Entre os elementos climáticos que influenciam o ciclo de maturação, a temperatura é considerada a mais relevante para os processos fisiológicos de maturação dos frutos (PEZZOPANE et al., 2008). A temperatura ideal para o desenvolvimento do C. canephora está entre 22 e $26{ }^{\circ} \mathrm{C}$ (DAMATTA; CARVALHO, 2006), podendo tolerar temperaturas de $37^{\circ} \mathrm{C}$ de dia e $30^{\circ} \mathrm{C}$ a noite, sendo que temperaturas superiores a $42^{\circ} \mathrm{C}$ de dia e $34^{\circ} \mathrm{C}$ à noite causam efeitos deletérios não-estomáticos irreversíveis na fotossíntese dessas plantas (MARTINS et al., 2016; RODRIGUES et al., 2016).

A avaliação do ciclo de maturação em função da soma de graus-dia se baseia na pressuposição de que a planta para completar uma fase fenológica necessita de um somatório térmico próprio, característico de sua fisiologia (PAULA CARVALHO et al., 2014; SALAZAR-PARRA et al., 2012).
Embora normalmente avaliado em classes, $\mathrm{o}$ ciclo de maturação do cafeeiro é uma característica de herança complexa, de expressão governada por vários genes influenciados pelo ambiente, $\mathrm{o}$ que resulta em uma característica quantitativa de distribuição contínua. No entanto, não foram encontrados na literatura pesquisas que avaliaram essa característica considerando sua natureza quantitativa. A predição dos parâmetros genéticos permite quantificar a fração da variação total que se deve ao efeito de genótipos e de ambientes, permitindo melhor predizer o comportamento das plantas. As técnicas ótimas de avaliação genética envolvem simultaneamente a predição de valores genotípicos e a estimação de componentes de variância (RESENDE et al., 2001). O procedimento para predição dos componentes de variância e dos valores genotípicos é o REML/ BLUP (Máxima Verossimilhança Restrita/ Melhor Predição Linear Não Viesada) ao nível de indivíduo (HENDERSON; QUAAS, 1976).

Nesse contexto, o objetivo desse trabalho foi quantificar os componentes genéticos do ciclo de maturação de 130 clones de C. canephora visando caracterizar os mecanismos de herança e a influência do ambiente sobre essa característica.

\section{MATERIAL E MÉTODOS}

\subsection{Estimativas do número de graus-dia e da soma térmica}

O ciclo de desenvolvimento dos frutos foi mensurado considerando o número de dias e soma térmica no período entre a data de florescimento e a data de colheita, quando aproximadamente $80 \%$ dos frutos estão na fase de maturação $\mathrm{M}_{3}$, de coloração vermelho claro e maduros fisiologicamente (MARCOLAN et al., 2009; MORAIS et al., 2008). No mês de dezembro de 2011, foi instalado no campo experimental da Embrapa no município de Ouro Preto do Oeste-RO experimento em delineamento de blocos casualizados, com seis repetições, quatro plantas por parcela em espaçamento de $3 \times 2 \mathrm{~m}$ para avaliação de 130 clones. De acordo com as Normais Climatológicas (BRASIL, 1992) o clima do município é do tipo Aw (classificação Köppen), definido como tropical úmido com estação chuvosa (outubro a maio) no verão e seca bem definida no inverno. Deficiência hídrica acumulada de junho a setembro $(\mathrm{DEF}=175 \mathrm{~mm})$ e excedente hídrico acumulado de novembro a abril $(\mathrm{EXC}=781 \mathrm{~mm})$ para $100 \mathrm{~mm}$ de retenção hídrica. A amplitude média anual varia de $21,2^{\circ} \mathrm{C}$ a $30,3^{\circ} \mathrm{C}$, sendo que as temperaturas mais elevadas ocorrem nos meses de julho e agosto. A precipitação média anual é de $1.939 \mathrm{~mm}$, com umidade relativa média do ar de $81 \%$. 
Dados climáticos foram coletados durante o período de julho de 2013 a dezembro de 2015 por meio de estação automática (1043'37.01'S e 62 $13^{\prime} 44.94$ ' $\left.\mathrm{W}\right)$ da marca METOS pertencente à CEPLAC (Comissão Executiva de Planejamento da Lavoura Cacaueira). As variáveis meteorológicas analisadas foram a precipitação $(\mathrm{mm})$, o déficit hídrico $(\mathrm{mm})$, a temperatura máxima $\left({ }^{\circ} \mathrm{C}\right)$, a temperatura mínima $\left({ }^{\circ} \mathrm{C}\right)$ e a temperatura média $\left({ }^{\circ} \mathrm{C}\right)$ (Figura 1$)$.

Embora o cafeeiro possa florescer até quatro vezes por ano, a sua florada principal ocorre nos meses de julho ou agosto, aproximadamente seis dias depois das primeiras chuvas após período de déficit hídrico. No ano agrícola 2013/2014 a florada principal do C. canephora ocorreu no dia 28 de julho e no ano agrícola seguinte 2014/2015 no dia 01 de agosto no município de Ouro Preto do Oeste - RO (10 $37^{\prime} 03^{\prime \prime} \mathrm{S}$ e $\left.62^{\circ} 51^{\prime} 50^{\prime \prime} \mathrm{W}\right)$.

Estimada a partir do contraste entre a temperatura-base e a temperatura média diária, a soma térmica fundamenta-se na quantificação do número de graus dias definida como a quantidade de calor efetivamente acumulada durante o dia, adequada para o crescimento do vegetal (PEZZOPANE et al., 2008):

$$
G D_{j}=\sum_{i=1}^{j}\left(T m_{i}-T b\right)
$$

em que:

$\mathrm{GD}_{\mathrm{J}}=$ graus dia acumulado durante o período em ${ }^{\circ} \mathrm{C} ; \mathrm{Tm}_{\mathrm{i}}=$ temperatura média do ar mensurada no i-ésimo dia em ${ }^{\circ} \mathrm{C} ; \mathrm{Tb}=$ temperatura basal inferior para a cultura do café igual a $15^{\circ} \mathrm{C}$ (BATISTASANTOS et al., 2011; DAMATTA; RAMALHO, 2006; WILLSON et al., 1999).

De forma que cada grau acima da temperatura basal $(\mathrm{Tb})$ corresponde a um graudia (DAMARIO; PASCALE; BURIOL, 2008). Diferentes estudos fisiológicos indicam uma amplitude de $10,2^{\circ}$ a $15,4^{\circ}$ da temperatura base do cafeeiro C. arabica (CAMARGO; CAMARGO, 2001; ORTOLANI et al., 2001). Segundo Damatta e Ramalho (2006) e Willson et al. (1999) em temperaturas menores do que $15^{\circ} \mathrm{C}$ a taxa de fotossíntese diminui drasticamente nas plantas de C. canephora.

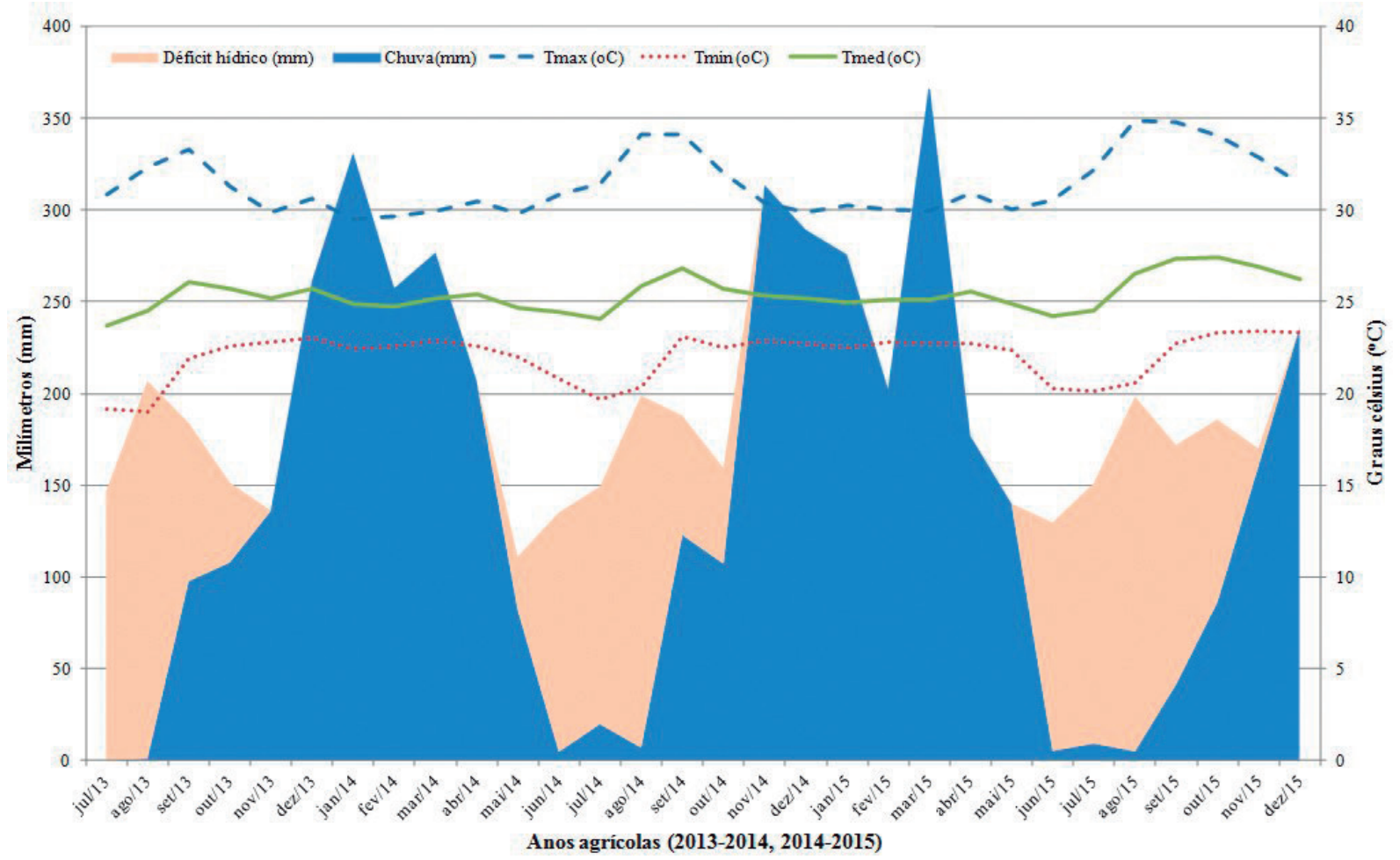

FIGURA 1 - Variáveis climáticas avaliadas no período de julho de 2013 a dezembro de 2015 no município de Ouro Presto do Oeste - RO, representadas por déficit hídrico $(\mathrm{mm})$, precipitação $(\mathrm{mm})$ e temperaturas máxima, mínimas e médias $\left({ }^{\circ} \mathrm{C}\right)$. 


\subsection{Estimativa dos parâmetros genéticos}

O procedimento REML (Restricted Maximum Likehood), máxima verossimilhança restrita, foi utilizado para estimar os componentes de variância e o método BLUP (Best Linear Unbiased Prediction), melhor preditor linear não viesado, foi utilizado para obter estimativas dos valores genotípicos (RESENDE et al., 2007). Esses procedimentos estão associados a um modelo linear misto que contém, além da média geral, efeito aleatório de tratamento (genótipos) e efeito fixo de ambiente. As estimativas dos valores genotípicos foram obtidas considerando os seguintes modelos lineares mistos para análise individual (1) e conjunta (2) em duas épocas (RESENDE, 2002):

$$
\mathrm{y}=\mathrm{Xb}+\mathrm{Zg}+\mathrm{e}
$$

Em que y: é o vetor de dados; $b$ :é o vetor dos efeitos de bloco, tomados como fixo; $\mathrm{g}$ : é $\mathrm{o}$ vetor dos efeitos genotípicos, tomados como aleatórios; $e$ : é o vetor de erros aleatórios. As letras maiúsculas representam as matrizes de incidência para os referidos efeitos.

$$
\mathrm{y}=\mathrm{Xm}+\mathrm{Za}+\mathrm{Wp}+\mathrm{Ts}+\mathrm{e}
$$

Em que y: é o vetor de dados; $m$ : é o vetor dos efeitos fixos das combinações mediçãorepetição, $a$ : é o vetor de efeitos genéticos aditivos individuais, considerados aleatórios, $p$ : é o vetor dos efeitos aleatórios de parcela, $s$ : vetor de efeitos permanentes de ambiente, tomados como aleatórios $e$ : é o vetor de erros aleatórios. As letras maiúsculas representam as matrizes de incidência para os referidos efeitos.

Entre os parâmetros genéticos mais importantes para a caracterização do controle genético e da eficiência do processo de seleção destacam-se a herdabilidade, a repetibilidade e a acurácia de seleção (CRUZ; CARNEIRO, 2006). A herdabilidade em sentido amplo mensura a proporção relativa entre os efeitos genotípicos e ambientais na expressão das características. É considerado o componente mais importante das estimativas de progresso genético obtidos com a propagação assexuada, que segundo Vencovsky e Barriga (1992), pode ser estimada por:

$$
h^{2}=\frac{\sigma_{g}^{2}}{\sigma_{g}^{2}+\sigma_{e}^{2}}
$$

Em que $h^{2}$ : é a herdabilidade em sentido amplo, $\sigma_{g}^{2}$ :é a variância genotípica, $\sigma_{e}^{2}$ : é a variância ămbiental.

O coeficiente de repetibilidade, que mensura a manutenção da superioridade genética ao longo do tempo, foi estimado para avaliar a precisão de se selecionar os clones com medidas repetidas obtidas conforme o estimador (CRUZ; CARNEIRO, 2006):

$$
\rho=\frac{\sigma_{g}^{2}+\sigma_{e p}^{2}}{\sigma_{y}^{2}}
$$

Em que $\sigma_{g}^{2}$ : é a variância genotípica, $\sigma_{e p}^{2}$ : variância permanente entre parcelas e: $\sigma_{y}^{2}$ variância fenotípica individual.

A acurácia seletiva é uma estimativa de correlação entre o valor genotípico verdadeiro e o estimado, $\left(\hat{r}_{\mathrm{g}}\right)$, sendo considerada uma importante medida $\mathrm{de}_{\mathrm{g}}$ qualidade dos procedimentos de seleção. A acurácia seletiva foi estimada de acordo com Resende (2002):

$$
\hat{r}_{g g}=\sqrt{\frac{m h_{g}^{2}}{1+(m-1) \rho}}
$$

Em que $m$ : é o número de medidas, $h_{g}^{2}:$ é a herdabilidade genotípica, $\rho$ : é a repetibilidăde. A acurácia seletiva varia de 0 a 1 , sendo que segundo classificação de Resende (2002), pode ser considerada como: muito alta $\left(\hat{r}_{z} \geq 0,9\right)$, alta $\left(0,7 \geq \hat{r}_{\mathrm{g}}>0,9\right)$, moderada $\left(0,5 \geq \hat{r}_{\mathrm{g}}>0,7\right)$, e baixa $\left(\hat{r}_{g}<0,5\right)$.

\subsection{Agrupamento dos genótipos de mesmo ciclo de maturação}

Visando agrupar os clones de mesmo grupo de maturação, a dissimilaridade entre os genótipos foi estimada considerando a diferença na soma térmica para a maturação dos frutos de acordo com o seguinte estimador (CRUZ; CARNEIRO, 2006):

$$
d_{i j}=\sqrt{\sum_{j}\left(\begin{array}{ll}
Y_{i} & Y_{j}
\end{array}\right)^{2}}
$$

Em que $d_{i j}$ : diferença na soma térmica entre o i-ésimo e o j-ésimo clone, $Y_{i}$ : soma térmica do i-ésimo clone, $Y_{\mathrm{i}}$ : soma térmica do j-ésimo clone. A partir da matriz de dissimilaridade da soma térmica foi estimado um dendrograma utilizando o método UPGMA (Unweighted Pair-Group Method Using Arithmetic Mean) de agrupamento hierárquico. 


\section{RESULTADOS E DISCUSSÃO}

O ciclo de maturação dos frutos de $C$. canephora é uma característica de natureza quantitativa, uma vez que os processos fisiológicos de desenvolvimento e maturação dos frutos possuem herança complexa influenciada pelo ambiente, que dependem da fisiologia e da energia acumulada pela planta (SERA et al., 2002). Ao se considerar a natureza quantitativa do processo de desenvolvimento dos frutos é possível, a partir dos valores fenotípicos, quantificar os componentes genéticos e ambientais associados à expressão dessa característica e prever sua estabilidade ao longo do tempo.

As análises de variância do número de dias e da soma térmica para o desenvolvimento dos frutos mostraram que a fonte de variação genótipos (clones) foi significativa nas épocas, de acordo com o teste $\mathrm{F}$ a $1 \%$ de probabilidade (Tabela 1 ). As magnitudes da variância genotípica e da variância ambiental indicam uma predominância do efeito de genótipos na expressão desta característica, resultado da expressão genética diferenciada entre plantas. Segundo Resende (2002), esta condição é fundamental para o progresso genético com a prática da seleção. $\mathrm{O}$ teste $\mathrm{F}$ também mostrou que a variância da fonte de variação genótipos foi aproximadamente dez vezes maior na primeira época de avaliação, período em que houve uma melhor distribuição de chuvas na região. Estimativas elevadas de variância genotípica também foram observadas por Ramalho et al. (2016), na avaliação da produção de café beneficiado ao longo de três safras.

As estimativas dos valores do coeficiente de variação experimental podem ser consideradas baixas indicando alta precisão experimental (FERRÃO et al., 2008) (Tabela 1). O coeficiente de variação é uma relação entre a média e o quadrado médio do resíduo que depende tanto das condições experimentais quanto da natureza da característica. Comparativamente, estimativas de coeficiente de variação entre $15 \%$ a $30 \%$ para a produção de café beneficiado indicam uma boa condução experimental (FERRÃO et al., 2008).

O desvio padrão da herdabilidade também foi interpretado como uma medida de qualidade das estimativas, sendo que na segunda época de avaliação observou-se a maior relação entre o desvio padrão e o valor da herdabilidade. Segundo Resende (2002), valores de desvio-padrão até $20 \%$ do valor da estimativa da herdabilidade indicam boa precisão dessas estimativas. Por sua vez a relação entre as estimativas do coeficiente de variação genético e o coeficiente variação ambiental quando próximos ou superiores à unidade, caracterizam condição favorável para a obtenção de ganhos com a seleção (RAMALHO, 2000) (Tabela 1).

Apesar da predominância do componente genético na expressão dessa característica, um mesmo genótipo pode apresentar diferenças no seu ciclo de maturação de um ano para o outro devido à ação do ambiente (PETEK; SERA; FONSECA, 2009). O coeficiente de repetibilidade $\rho \geq 0,7$ indicou tendência das plantas em manter o seu ciclo de maturação ao longo do tempo (Tabela 2).

A dispersão no plano das estimativas dos valores genotípicos do número de dias e da soma térmica necessária para desenvolvimento e maturação dos frutos, mostra a tendência das plantas de manter seu comportamento ao longo do tempo; e a maior precisão da soma térmica para predizer o comportamento dessa característica (Figura 2). As estimativas do coeficiente de determinação mostram a correlação positiva e de alta magnitude, observada entre as avaliaçõesrealizadas em um ano agrícola em comparação com o ano agrícola seguinte (Figura 2).

Todas as estimativas dos parâmetros genéticos interpretadas indicaram maior precisão da soma térmica em comparação ao número de dias para maturação dos frutos em C. canephora. A soma térmica para o desenvolvimento dos frutos esteve associada a uma herdabilidade média de 0,95 no ano agrícola de 2013-2014 e de 0,93 no ano agrícola de 2014-2015, o que segundo classificação de Resende (2002), indica alta precisão nas inferências dos valores genotípicos $r_{\mathrm{gg}} \geq 0,9$. Entre os elementos climáticos, a temperatura do ar é um dos mais importantes, uma vez que os processos fisiológicos do cafeeiro são influenciados pela utilização da energia radiante mensurada na forma da soma térmica necessária para o desenvolvimento dos frutos (CARVALHO et al., 2011; PEZZOPANE et al., 2003).

Para a produção de café com qualidade de bebida é importante a realização da colheita na época correta, quando a maior parte dos frutos encontra-se fisiologicamente madura, reduzindo a proporção de frutos verdes misturados aos frutos maduros (TEIXEIRA et al., 2015). A adoção de tecnologias como a colheita escalonada, que consiste em utilizar clones superiores de ciclo de maturação diferenciado, subsidia a realização da colheita ao longo do tempo (BARDINCAMPAROTTO; CAMARGO; MORAES, 2012; PETEK; SERA; FONSECA, 2009). 
TABELA 1 - Parâmetros genéticos para características número de dias (ND) e soma térmica ( $\sum T$ ) para a maturação dos frutos, estimados a partir da avaliação de 130 clones de Coffea canephora, nos anos agrícolas de 2013-2014 e 2014-2015 no município de Ouro Preto do Oeste, Rondônia.

\begin{tabular}{|c|c|c|c|c|}
\hline Parâmetros genéticos & $\begin{array}{c}\text { ND } \\
\text { 2013-2014 }\end{array}$ & $\begin{array}{c}\text { ND } \\
\text { 2014-2015 }\end{array}$ & $\underset{\mathbf{2 0 1 3}-2014}{\sum T}$ & $\sum_{\mathbf{2 0 1 4}-2015}$ \\
\hline Variância genotípica $\left(\sigma_{g}^{2}\right)$ & 274,8 & 208,45 & 27874,38 & 20895,83 \\
\hline Variância residual $\left(\sigma_{e}^{2}\right)$ & 82,12 & 114,69 & 8070,25 & 9363,54 \\
\hline Variância fenotípica $\left(\sigma_{f}^{2}\right)$ & 356,93 & 323,14 & 35944,63 & 30259,37 \\
\hline Estimativa do teste da ANOVA $(F)$ & $23,26 * *$ & $13,13 * *$ & $24,02 * *$ & $15,77 * *$ \\
\hline Herdabilidade no sentido amplo $\left(h_{g}^{2}\right)^{1}$ & $0,77 \pm 0,06$ & $0,65 \pm 0,08$ & $0,78 \pm 0,09$ & $0,69 \pm 0,09$ \\
\hline Herdabilidade média de clones $\left(h_{n n}^{2}\right)$ & 0,95 & 0,92 & 0,95 & 0,93 \\
\hline Acurácia da seleção clonal $\left(\mathrm{AC}_{\text {clon }}\right)$ & 0,97 & 0,96 & 0,98 & 0,96 \\
\hline Coeficiente de variação genotípica $\left(\mathrm{CV}_{\mathrm{g}}\right)$ & 5,71 & 5,08 & 5,61 & 4,86 \\
\hline Coeficiente de variação residual $\left(\mathrm{CV}_{\mathrm{e}}\right)$ & 3,12 & 3,77 & 3,02 & 3,25 \\
\hline Coeficiente de variação relativa $\left(\mathrm{CV}_{\mathrm{r}}\right)^{2}$ & 1,83 & 1,34 & 1,86 & 1,49 \\
\hline Variância do erro( $P E V)$ & 13,03 & 14,51 & 1283,12 & 1452,14 \\
\hline DP do valor genotípico predito ( $S E P$ ) & 3,61 & 4,18 & 35,82 & 38,11 \\
\hline Média geral $(\mu)$ & 289,93 & 284,02 & 2971,05 & 2972,34 \\
\hline
\end{tabular}

TABELA 2 - Parâmetros genéticos da análise conjunta do número de dias (ND) e da soma térmica ( $\sum T$ ) para a maturação dosfrutos de 130 clones de Coffea canephora avaliados nos anos agrícolas 2013-2014 e $2014-2015$. Campo Experimental de Ouro Preto do Oeste (RO).

\begin{tabular}{lcc}
\hline \multicolumn{1}{c}{ Parâmetros genéticos } & ND & $\sum T$ \\
\hline Variância genotípica $\left(\sigma_{g}^{2}\right)$ & 207,56 & 20954,89 \\
Variância dos efeitos permanentes de ambiente $\left(\sigma_{\varphi}^{2}\right)$ & 24,29 & 2685,15 \\
Variância residual $\left(\sigma_{e}^{2}\right)$ & 91,99 & 8088,78 \\
Variância fenotípica individual $\left(\sigma_{f}^{2}\right)$ & 323,84 & 31728,83 \\
Herdabilidade sentido amplo $\left(h_{g}^{2}\right)^{1}$ & $0,64 \pm 0,05$ & $0,66 \pm 0,05$ \\
Repetibilidade $(\rho){ }^{2}$ & $0,72 \pm 0,06$ & $0,74 \pm 0,06$ \\
Coeficiente de determinação dos efeitos permanentes $\left(c_{\text {perm }}^{2}\right)$ & 0,07 & 0,08 \\
Média geral & 287,71 & 2979,69 \\
\hline
\end{tabular}

${ }^{1}$ Herdabilidade em sentido amplo associada a seu desvio padrão, ${ }^{2}$ Repetibilidade associada a seu desvio padrão 


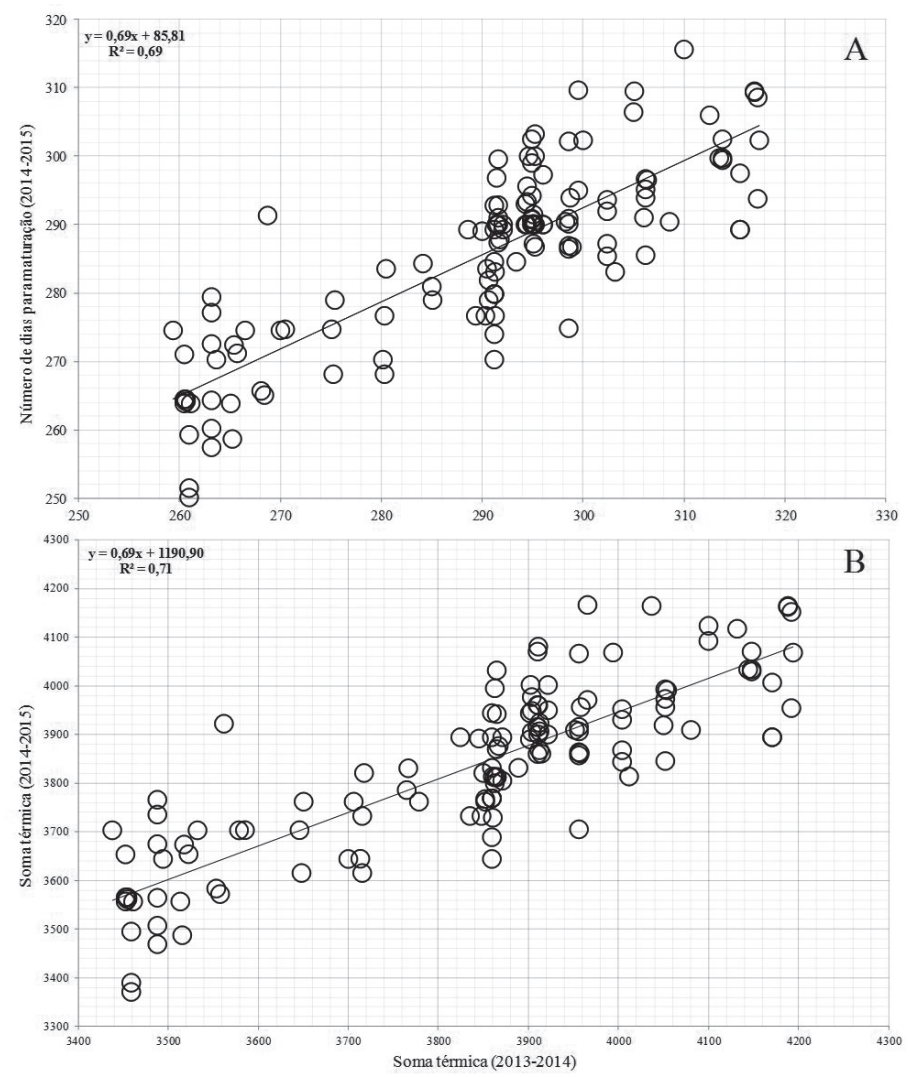

FIGURA 2 - Dispersão no plano dos valores genotípicos do número de dias (A) e correlação da soma térmica (B) para maturação dos frutos de 130 clones de Coffea canephora avaliados nos anos agrícolas de 2013-2014 e 20142015 no município de Ouro Preto do Oeste - Rondônia.

No ano de 2013, o Instituto Capixaba de Pesquisa Assistência Técnica e Extensão Rural (INCAPER) lançou três diferentes variedades comerciais de ciclo de maturação precoce, intermediário e tardio, respectivamente. No ano de 2012, a Embrapa Rondônia lançou a variedade BRS Ouro Preto, uma variedade de ciclo intermediário adaptada especificamente para as condições de solo e clima do Estado de Rondônia.

Como forma de quantificar a variabilidade genética e agrupar os clones de ciclo de maturação semelhante foi utilizada técnica de agrupamento hierárquico para a obtenção de um diagrama em árvore (Figura 3). Diferentes métodos podem ser utilizados para determinar intervalos de uma variável quantitativa. Machado e Figueiredo Filho (2006) sugerem a utilização do estimador desenvolvido a partir da distribuição binomial. Por sua vez Scott (1979) sugere a classificação de uma variável quantitativa em intervalos, definidos em função da amplitude total e do desvio padrão normalizado. A utilização de técnicas de agrupamento hierárquico, como realizado nesse trabalho, permitiu quantificar e visualizar o número de classes mais apropriado em função da variabilidade contida nos dados. A definição dos pontos de corte estabelecido entre grupos de maior divergência permitiu classificar os clones em três grupos de maturação diferenciada, baseado na soma térmica necessária para a maturação dos frutos.

A desuniformidade na distribuição de chuvas na segunda época de avaliação resultou em maior desuniformidade de maturação que pode ser observada nos maiores valores de divergência observados no dendrograma (Figura 3). No dendrograma foi possível observar, três grupos de maturação distintos que se mantiveram ao longo do tempo. Um grupo precoce com soma térmica para maturação de 2660 a 2821 no primeiro ano e 2621 a 2711 no segundo ano agrícola avaliado. Um grupo intermediário com soma térmica para maturação de 2875 a 3067 no primeiro ano e 2880 a 3090 no segundo ano agrícola avaliado. 


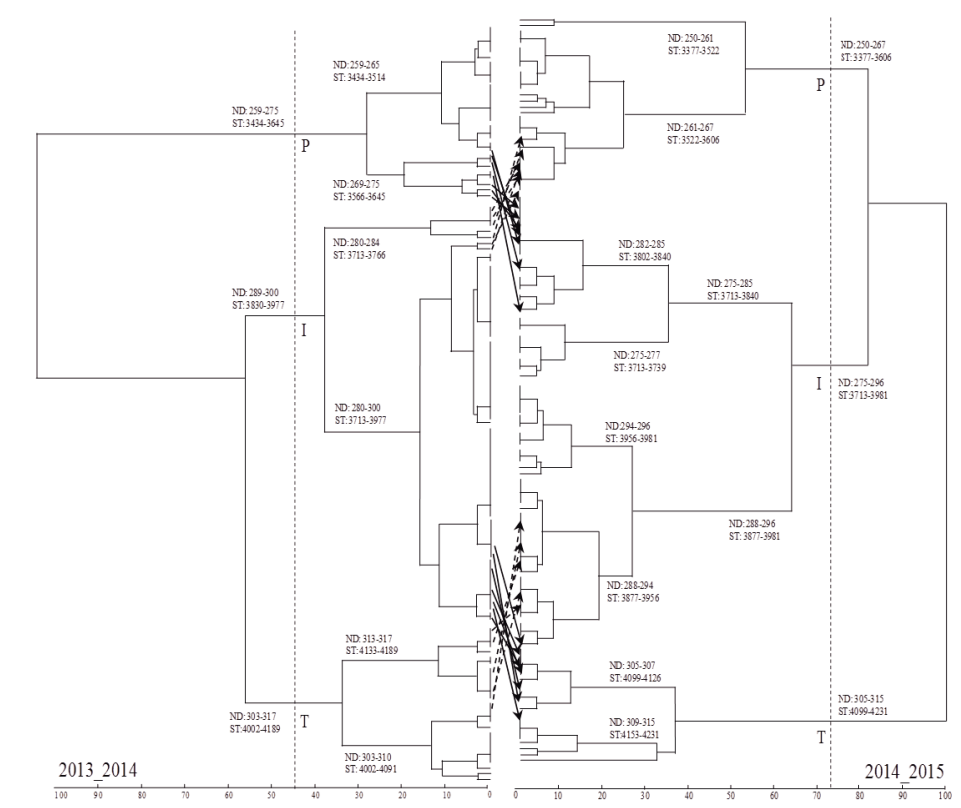

FIGURA 3 - Dendrograma obtido pelo método de UPGMA, classificando os 130 clones de Coffea canephora nos anos agrícolas 2013/2014 e 2014/2015 em função das estimativas da soma térmica para a maturação dosfrutos. As setas indicam as mudanças nos agrupamentos ocorridas de um ano para o outro.

E um grupo tardio com soma térmica para maturação de 3102 a 3240 no primeiro ano e 3140 a 3274 no segundo ano agrícola avaliado (Figura 3).

$\mathrm{Na}$ prática, os agricultores já realizam a colheita dos clones com aproximadamente 20 dias de diferença entre ciclo. Partelli et. al. (2014) em seus trabalhos observaram plantas de ciclos de maturação precoce, média ou intermediárias, tardias e extremamente tardias.

Apesar da predominância do componente genotípico na expressão dessa característica foram observadas diferenças na classificação de um ano para o outro (Figura 3). Dos 130 clones avaliados, 105 clones mantiveram-se no mesmo agrupamento de um ano para o outro (80\%) e 25 clones foram classificados em diferentes grupos (20\%). Os clones que apresentaram mudanças em sua classificação foram aqueles que amadureceram com valores de soma térmica próximos aos limites dos grupos, definido em função da própria variabilidade dos dados (Figura 3 ).

Tanto o florescimento do cafeeiro quanto a taxa de crescimento dos frutos são afetados por fatores climáticos que influenciam na uniformidade de maturação e período da colheita. No entanto, o entendimento da variabilidade genética permite selecionar plantas com valores de soma térmica características de cada grupo e que mantém sua maturação estável ao longo do tempo.

\section{CONCLUSÃO}

A caracterização dos componentes genéticos do desenvolvimento e maturação dos frutos de C. canephora demonstra predominância da variância genotípica na expressão dessa característica associada à uma alta eficiência de seleção. Observou-se maior precisão da soma térmica em comparação ao número de dias para avaliar o desenvolvimento e a maturação dos frutos de C. canephora. A utilização de técnicas de agrupamento hierárquico permitiu definir o número de classes mais apropriado em função da variabilidade contida nos dados. Vinte por cento dos clones apresentaram diferenças na classificação de um ano para o outro devido à ação do ambiente. O agrupamento dos clones de ciclo de maturação semelhante subsidia a composição de variedades comerciais que além de outros atributos favoráveis apresentem também ciclo de maturação mais uniforme e estável.

\section{AGRADECIMENTOS}

Ao Conselho Nacional de Desenvolvimento Científico e Tecnológico (CNPq) pela concessão de bolsa e ao Consórcio Brasileiro de Pesquisa e Desenvolvimento do Café (CPC) pelo apoio financeiro e a todos os técnicos agrícolas e operários rurais do campo experimental da Embrapa em Ouro Preto do Oeste, pela dedicação ao trabalho ao longo dos anos. 


\section{REFERÊNCIAS}

BARDIN-CAMPAROTTO, L.; CAMARGO, M.B.P.; MORAES, J.F.L. Época provável de maturação para diferentes cultivares de café arábica para o Estado de São Paulo. Ciência Rural, Santa Maria, v. 42, p. 594599, 2012.

BATISTA-SANTOS, P. et al. The impact of cold on photosynthesis in genotypes of Coffea spp.photosystem sensitivity, photoprotective mechanisms and gene expression. Journal of Plant Physiology, Jena, v. 168, n. 8, p. 792-806, 2011.

BRASIL. Ministério da Agricultura e Reforma Agrária. Secretaria Nacional de Irrigação. Normais climatológicas: 1961-1990. Brasília, DF:Departamento Nacional de Meteorologia, 1992. 84p.

CAmargo, A. P. de; CAMARGo, M. B. P. de. Definição e esquematização das fases fenológicas do cafeeiro arábica nas condições tropicais do Brasil. Bragantia, Campinas, v. 60, n. 1, p. 65-68, mar. 2001.

CARVALHO, H. P. et al. Índices bioclimáticos para a cultura de café. Revista Brasileira de Engenharia Agrícola e Ambiental, Campina Grande, v. 15, n. 6, p. 601-606, 2011.

COELHO, M. R. Coeficiente de cultura (kc) e desenvolvimento inicial de duas variedades de cafeeiro (Coffea arabica L.) associados a graus-dia. 2004. 75 p. Dissertação (Mestrado em Engenharia Agrícola) - Universidade Federal de Lavras, Lavras, 2004.

CRUZ, C.D.; CARNEIRO, P.S.C. Modelos biométricos aplicados ao melhoramento genético. 2.ed. Viçosa, MG: Ed. UFV, 2006. v.2, 586p.

CUNHA, A.R.; VOLPE, C.A. Curvas de crescimento do fruto de cafeeiro cv. Obatã IAC 1669-20 em diferentes alinhamentos de plantio. Semina: Ciências Agrárias, Londrina, v.32, n.1, p.49-62, 2011.

DAMARIO, E. A.; PASCAlE, A. J.; BURIOL, G. A. Disponibilidades de calor para os cultivos no Estado do Rio Grande do Sul. Revista do Centro de Ciências Rurais, Santa Maria, v. 6, n. 2, p. 129-165, 2008.

DAMATTA, F. M.; RAMALHO, J. D. C. Impacts of drought and temperature stress on coffee physiology and production: a review. Brazilian Journal of Plant Physiology, Londrina,v. 18, n. 1, p. 55-81, 2006.

DAVIS, A. P. et al. Growing coffee: Psilanthus (Rubiaceae) subsumed on the basis of molecular and morphological data; implications for the size, morphology, distribution and evolutionary history of Coffea. Botanical Journal of the Linnean Society, London, v. 167, n. 4, p. 357-377, 2011.

DUBBERSTEIN, D. et al. Concentration and accumulation of macronutrients in leaf of coffee berries in the Amazon, Brazil. Australian Journal of Crop Science, Brisbane, v. 10, p. 701-710, 2016.

FERRÃO, R. G. et al. Genetic parameters in Conilon coffee. Pesquisa Agropecuária Brasileira, Brasília, v. 43, n. 1, p. 61-69, jan. 2008.

HENDERSON, C. R.; QUAAS, R. L. Multiple trait evaluation using relatives' records. Journal of Animal Science, Washington, v. 43, n. 6, p. 1188-1197, 1976.

IAFFE, A. et al. Estimativa de temperatura-base e grausdia com correção pelo fotoperíodo do florescimento à colheita de café em Campinas, SP. In: SIMPÓSIO DE PESQUISA DOS CAFÉS DO BRASIL, 2., 2001. Anais... Brasília: EMBRAPA Café, 2001. p. 47-47.

LAVIOLA, B. G. et al. Acúmulo de nutrientes em frutos de cafeeiro em quatro altitudes de cultivo: cálcio, magnésio e enxofre. Revista Brasileira de Ciência do Solo, Viçosa, v. 31, p. 1451-1462, 2007.

LIMA, E.P.; SILVA, E.L. da. Temperatura base, coeficientes de cultura e graus-dia para cafeeiro arábica em fase de implantação. Revista Brasileira de Engenharia Agrícola e Ambiental, Campina Grande, v. 12, n. 3, p. 266-273, 2008.

MACHADO, S.do A.; FIGUEIREDO FILHO, A. Dendrometria. 2. ed. Curitiba: Ed. Unicentro, 2006. $316 \mathrm{p}$.

MARCOLAN, A. L. et al. Cultivo dos cafeeiros conilon e Robusta para Rondônia. Porto Velho: EMBRAPA Rondônia, 2009. 67 p. (EMBRAPA Rondônia: Sistema de Produção, 33).

MARTINS, M. Q. et al. Protective response mechanisms to heat stress in interaction with High $\left[\mathrm{CO}_{2}\right]$ Conditions in Coffea spp. Frontiers in Plant Science, Lausana, v. 7, p. 946-968, 2016.

MORAIS, H. et al. Escala fenológica detalhada da fase reprodutiva de Coffea arabica. Bragantia, Campinas,v. 67, n. 1, p. 257-260, 2008.

MOURA, S. C. S. R. de et al. Avaliações físicas, químicas e sensoriais de blends de café arábica com café canephora (robusta). Brazilian Journal Food Technology, Campinas, v. 10, n. 4, p. 271-277, 2007. 
NUNES, F. L. et al. Modelos agrometeorológicos de estimativa da duração do estádio floração-maturação para três cultivares de café arábica. Bragantia, Campinas, v. 69, n. 4, p. 1011-1018, 2010.

OMETTO, J. C. Bioclimatologia vegetal. São Paulo: Agronômica Ceres, 1981. 440 p.

ORTOLANI, A. A. et al. Regionalização da época de maturação e qualidade natural de bebida do café arábica no Estado de São Paulo. In: CONGRESSO BRASILEIRO DE AGROMETEOROLOGIA, 12., 2001, Fortaleza. Resumos Expandidos... Fortaleza: SBA, 2001. v. 1, p. 53-54.

PARTELLI, F. L. et al. Dry matter and macronutrient accumulation in fruits of conilon coffee with different ripening cycles. Revista Brasileira de Ciência do Solo, Viçosa, v. 38, n. 1, p. 214-222, 2014.

Seasonal vegetative growth of different age branches of conilon coffee tree. Semina: Ciências Agrárias, Londrina, v. 31, n. 3, p. 619-626,2010.

PAULA CARVALHO, H. et al. Classificação do ciclo de desenvolvimento de cultivares de cafeeiro através da soma térmica. Coffee Science, Lavras, v. 9, n. 2, p. 237-244, 2014

PETEK, M. R.; SERA, T.; FONSECA, I. C. de B. Exigências climáticas para o desenvolvimento e maturação dos frutos de cultivares de Coffea arabica. Bragantia, Campinas, v. 68, n. 1, p. 169-181, 2009.

PEZZOPANE, J. R. M. et al. Escala para avaliação de estádios fenológicos do cafeeiro arábica. Bragantia, Campinas, v. 62, n. 3, p. 499-505, 2003.

Exigência térmica do café arábica cv. Mundo Novo no subperíodo florescimento-colheita. Ciência e Agrotecnologia, Lavras, v. 32, n. 6, p.1781-1786, nov./ dez. 2008 .

Zoneamento de risco climático para a cultura do café Conilon no Estado do Espírito Santo. Revista Ciência Agronômica, Fortaleza, v. 41, n. 3, p. 341348, 2010.

RAMALHO, A. R. et al. Progresso genético da produtividade de café beneficiado com a seleção de clones de cafeeiro 'Conilon'. Revista Ciência Agronômica, Fortaleza, v. 47, n. 3, p. 516-523, 2016.

RAMALHO, M.A.P. Experimentaçãoem genética e melhoramento de plantas. Lavras: Ed. UFLA, 2000.326 p.
RESENDE, M.D.V. Genética biométrica e estatística no melhoramento de plantas perenes. Brasília, DF: EMBRAPA Informação Tecnológica, 2002. 975p.

RESENDE, M.D.V. et al. Estimativas de parâmetros genéticos e predição de valores genotípicos no melhoramento do cafeeiro pelo procedimento REML/ BLUP. Bragantia, Campinas, v.60, n.3, p.185-193, 2001.

REZENDE, F. C. et al. Características produtivas do cafeeiro (Coffea arabica L. cv., Topázio MG-1190), recepado e irrigado por gotejamento. Coffee Science, Lavras, v. 1, n. 2, p. 103-110, 2007.

RIBEIRO, B. B. et al. Avaliação química e sensorial de blends de Coffea canephora Pierre e Coffea arabica L. Coffee Science, Lavras, v. 9, n. 2, p. 178-186, 2014.

ROCHA, R. B. et al. Caracterização e uso da variabilidade genética de banco ativo de germoplasma de Coffea canephora Pierre ex Froehner. Coffee Science, Lavras, v. 8, n. 4, p. 478-485, 2014.

RODRIGUES, W. P. et al. Long-term elevated air $\left[\mathrm{CO}_{2}\right]$ strengthens photosynthetic functioning and mitigates the impact of supra-optimal temperatures in tropical Coffea arabica and C. canephora species. Global Change Biology, Malden, v. 22, n. 1, p. 415-431, 2016.

SALAZAR-PARRA, C. et al. Climate change (elevated $\mathrm{CO} 2$, elevated temperature and moderate drought) triggers the antioxidant enzymes' response of grapevine cv. Tempranillo, avoiding oxidative damage. Physiologia Plantarum, Malden, v. 144, n. 2, p. 99110, 2012.

SCOTT, D. W. On optimal and data-based histograms. Biometrika, Oxford, v. 66, n. 3, p. 605-610, May 1979.

SERA, T. et al. Melhoramento do cafeeiro: variedades melhoradas no Instituto Agronômico do Paraná (IAPAR). O estado da arte de tecnologias na produção de café. Viçosa, MG: UFV,2002. p. 217-251.

TEIXEIRA, A. L. et al. Selection of arabica coffee progenies tolerant to heat stress. Ciência Rural, Santa Maria, v.45, n.7, p. 1228-1234, 2015.

VENCOVSKY, R.; BARRIGA, P. Componentes da variação fenotípica: análise em vários ambientes. In:_ Genéticabiométrica nofitomelhoramento. Ribeirão Preto: Sociedade Brasileira de Genética, 1992. p.233-333.

WILLSON, K. C. et al. Coffee, cocoa and tea. Oxon: CABI, 1999. 